\title{
PARTY IDENTIFICATION AND PARTY CLOSENESS IN COMPARATIVE PERSPECTIVE
}

\author{
Samuel H. Barnes, M. Kent Jennings, \\ Ronald Inglehart, and Barbara Farah
}

\begin{abstract}
The present analysis uses data from 1974 and $1981 \mathrm{U}$. S. cross sections, which incorporate a panel, to compare the standard NES measure of party identification (ID) with a measure of partisanship derived from a party closeness question widely employed in cross-national research. Important features of the two scales are examined by transforming the closeness measure into a scale of very close, fairly close, not very close, and no preference corresponding to the seven-point ID scale. The scales are highly correlated and are similar in their reliability. More than $\mathbf{7 5 \%}$ of the "independents" in the ID scale choose a party in the closeness version, and over half of these select the "fairly close" category. Respondents do not volunteer that they are independents when that alternative is not stated in the question.
\end{abstract}

The conceptualization and measurement of partisanship have generated an enduring controversy in the study of electoral behavior. The issues are complicated in a single country; complexities multiply in a cross-national context. This article explores two measures of partisanship employed in two U. S. cross sections and a panel study: One is the traditional party identification (ID) measure associated with the University of Michigan electoral school; the other is a party closeness measure widely employed in European and comparative studies. We document both similarities and differences in the measures. We examine the political complexion of the electorate according to the two measures and pay particular attention to the differing images of partisanship and independence that they evoke. Finally, we explore how the two measures relate to other attitudes and behaviors, especially the vote.

Most research on American politics uses the ID measure developed and employed in the University of Michigan's electoral studies. It has proven to

Samuel H. Barnes, M. Kent Jennings, and Ronald Inglehart, The University of Michigan. Barbara Farah, The New York Times. Address correspondence to: Dr. Samuel H. Barnes, 4010 Institute for Social Research, University of Michigan, Ann Arbor, MI 48106. 
have utility and durability in the study of electoral behavior and political parties. Yet many aspects of the measurement remain controversial, including in particular the question of partisan versus independent identification. Some say the two identifications are not incompatible, because they tap separate dimensions (Dennis, 1981a, b, 1982; Kamieniecki, 1985; Weisberg, 1980). Others note that the pure independent category combines citizens who are politically engaged yet reluctant to name a party with others who are in fact nonpartisan or even apolitical (Miller and Wattenberg, 1983; Craig, 1985). Intransitivities exist in the ID measure: Patterns of relationships with other variables suggest that many independents are actually more partisan than weak identifiers (Petrocik, 1974; Bastedo and Lodge, 1980; Campbell, 1984; Keith, Magleby, Nelson, Orr, Westlye, and Wolfinger, 1986; Valentine and van Wingen, 1980). Students of cross-national electoral behavior claim that the phenomenon of independence is confined to the United States (Budge, Crewe, and Farlie, eds., 1976).

The present analysis introduces party closeness as an alternative measure of partisanship and compares it with ID. Although the marginals generated by the two measures do not differ greatly, party closeness has some important advantages. It resolves many of the problems associated with independence in American electoral research. It elicits a spontaneous partisan preference from a higher percentage of respondents than does ID. It clarifies the distinctions between partisans and apoliticals. The closeness measure aligns respondents along a seven-point scale as in the ID version, but with fewer of the intransitivities exhibited by the latter. Party closeness possesses the high reliability of the ID measure. The closeness measure is clearly superior for cross-national comparisons, as the ID measure is difficult to administer in multiparty systems. When the party closeness measure is used, many "independents" on the ID scale spontaneously name a party; they do not volunteer that they are independents when that alternative is not presented to them.

The alternative measure helps clarify the meaning and consequences attached to the usage of the traditional measure. The face content of the measures suggests that the two may tap somewhat different qualities. One captures closeness to a party, which may be quite different from feeling oneself a partisan of that party, of "being" a Democrat or a Republican. They offer somewhat different profiles of the partisan landscape. Nevertheless, except for analyses focusing on the nature of "independence," the two measures are for most purposes interchangeable. This conclusion is reassuring to comparative scholars who have relied on the ID measure for estimating partisanship in the United States. 


\section{THE TWO MEASURES OF PARTISANSHIP}

In the University of Michigan's CPS/NES electoral studies, the respondent is asked, "Generally speaking, do you usually think of yourself as a Republican, a Democrat, an independent, or what?" Those naming a party are asked, "Would you call yourself a "strong" (Republican/Democrat) or a "not very strong" (Republican/Democrat)? Independents or "other" are asked, "Do you think of yourself as closer to the Republican or Democratic party?" The format provides the respondent with the names of the two major parties and also suggests "independent" as an equally acceptable alternative.

Questions used to elicit partisan preference in other countries do not suggest independence as an alternative, and they seldom name the parties. Party closeness is one of these widely used alternative measures of partisanship. It has been used by Michigan scholars in a series of foreign surveys, by other researchers in several countries, and in an eight-nation study of political action in the mid $1970 \mathrm{~s}^{1}$ In three of the eight countries included in the political action project-the United States, Germany, and the Netherlands-a second survey, incorporating a panel, was executed in 1979-1981. The present analysis focuses on the American data from these studies, as both the party closeness and ID questions were asked in both years. ${ }^{2}$

The party closeness question asked respondents, "Which political party do you usually feel closest to?"3 Those who name a party are then asked, "Would you say you feel very close, fairly close, or not very close to that party?" The resulting fourfold distributions (ignoring party designation) of the American cross-section samples for the two years are given in Table 1. The parallel distributions for the ID scales are given in Table 2.

Several aspects of these marginals merit emphasis. The apparent number of (spontaneous) partisans varies dramatically between the two measures. Fewer than one-fifth of the respondents failed to select a party in the closeness version even though parties were not named; a corollary is that respondents did not volunteer "independent" when that stimulus was not provided. By contrast, two-fifths of the samples failed to select a party without further prompting in the ID format. The partisan landscape looks

TABLE 1. Fourfold Distributions of the American Cross-Section Samples

\begin{tabular}{llllll}
\hline & $\begin{array}{c}\text { Very } \\
\text { close }\end{array}$ & $\begin{array}{c}\text { Fairly } \\
\text { Close }\end{array}$ & $\begin{array}{c}\text { Not Very } \\
\text { Close }\end{array}$ & $\begin{array}{c}\text { Total with } \\
\text { Unprompted } \\
\text { Preferences }\end{array}$ & $\begin{array}{c}\text { No } \\
\text { Preferences }\end{array}$ \\
\cline { 2 - 6 } 1974 & $14.1 \%$ & $41.6 \%$ & $28.1 \%$ & $83.8 \%$ & $16.2 \%$ \\
1981 & 14.5 & 47.7 & 24.0 & 86.2 & 13.8 \\
\hline
\end{tabular}


TABLE 2. Parallel Distributions for the ID Scales

\begin{tabular}{|c|c|c|c|c|c|c|}
\hline & $\begin{array}{c}\text { Strong } \\
\text { Partisans }\end{array}$ & $\begin{array}{c}\text { Weak } \\
\text { Partisans }\end{array}$ & $\begin{array}{l}\text { Total with } \\
\text { Unprompted } \\
\text { Preferences }\end{array}$ & $\begin{array}{l}\text { Independent } \\
\text { Leaners }\end{array}$ & $\begin{array}{c}\text { Total } \\
\text { with } \\
\text { Preferences }\end{array}$ & $\begin{array}{c}\text { No } \\
\text { Preference } \\
\text { \& Pure } \\
\text { Independent }\end{array}$ \\
\hline 197 & $22.9 \%$ & $36.7 \%$ & $59.6 \%$ & $21.9 \%$ & $81.5 \%$ & $18.5 \%$ \\
\hline 1981 & 25.1 & 34.3 & 59.4 & 28.3 & 87.7 & 12.3 \\
\hline
\end{tabular}

quite different when viewed through these two lenses: It is one thing to say that two-fifths of the American public has no party preference and quite another to say that less than one-fifth does.

Some respondents may have been encouraged to claim a party in the closeness version by the fact that they were not immediately reminded that they could use independent or "no party" as an alternative; others may have recalled that they had previously been asked the ID questions in the same interview. But why would so many have remembered that they had selected a party, yet so few have recalled that they had responded "independent" to that question? In its current format, the closeness question does not distinguish between "independent" and "no partisan preference" responses. But even if all of those in category four of the closeness measure considered themselves to be pure independents, which is highly unlikely, the percentage of independents could be only a bit more than one-third of that in the ID measure.

Question placement does not account for these differences. Schuman and Presser (1981, p. 54) found that fatigue, which may ensue near the end of a long interview, often reduces substantive responses. Two pieces of evidence suggest that question placement and fatigue are not responsible for the differences between the two measures. The first is that the closeness question came at the very end of the interview, while ID was asked near the midway point. Yet in 1974, there were slightly fewer instances of "no preference" in the closeness scale compared with pure independence on the ID measure, with the situation being reversed in 1981. The second piece of evidence concerns the length of the interviews. Dividing interviews into three groups according to length of interview shows no fatigue effects in the longer interviews. In 1974, interview length had no impact at all on the percentage of identifiers. In 1981, the group with the longest interviews had $7 \%$ more identifiers than the shortest. This was largely accounted for by the greater length of Republican interviews in that year. ${ }^{*}$

If the traditional measure generates seemingly fewer outright partisans than does the closeness measure, it nevertheless produces higher proportions of intense partisans. Whereas about one in four of the total set of respondents in each year is classified as a strong Democrat or Republican 
in the traditional measure, only about one in six is classified "very close" in the alternative measure. As many studies have demonstrated, such intense partisans are a special breed; the closeness version understates their presence. Perhaps this is in part due to partisans being presented with three alternatives in the closeness version and only two (strong and not very strong) in the ID one.

The characteristics of each measure are constant at both points in time. That such similar overall results were obtained across the seven years indicates that these similarities and differences are inherent in the measures rather than being the reflection of peculiar circumstances.

\section{SIMILARITIES IN THE TWO MEASURES}

What difference does it make whether one or the other measure is used? To examine this question we need to render the categories of the two measures comparable. We accomplish this by arranging the respondents on the closeness scale from very close Democrat to very close Republican, with those without a partisan preference at the midpoint. ${ }^{5}$ Remember that the three categories of closeness were solicited after the respondent had indicated a feeling of closeness to a party, so that the "not very close" category consists of respondents who said they felt "close" to a party, but who chose "not very close" rather than "very close" or "fairly close" on the follow-up question. This seven-point scale parallels the seven-point ID scale ranging from strong Democrat to strong Republican with pure independents at the midpoint, as follows:

\begin{tabular}{lccccccc}
\multirow{4}{*}{ ID } & 1 & 2 & 3 & 4 & 5 & 6 & 7 \\
& Strong & Weak & Ind. & Ind. \& & Ind. & Weak & Strong \\
Closeness & Dem. & Dem. & Dem. & no pref. & Rep. & Rep. & Rep. \\
& Very & Fairly & Not & No & Not & Fairly & Very \\
& close & close & close & pref. & close & close & close \\
& Dem. & Dem. & Dem. & & Rep. & Rep. & Rep.
\end{tabular}

The marginals for the two scales in the 1974 and 1981 cross sections are given in Table $3 .^{6}$ Now the two measures resemble each other to a far greater extent. The leaners of the ID scale have been made to parallel the not-close partisans of the other scale. As could be inferred from previous observations, perhaps the most significant contrast lies in the presence of more intense devotees of each party according to the traditional measure.

Congruence of the measures at the aggregate level does not necessarily mean congruence at the individual level. In fact, however, there is a high individual-level correspondence between these two measures at both points 
TABLE 3. Marginals for the Two Scales in the 1974 and 1981 Cross Sections

\begin{tabular}{lccccccc}
\hline & 1 & 2 & 3 & 4 & 5 & 6 & 7 \\
\cline { 2 - 7 } 1974 ID & $16 \%$ & $23 \%$ & $14 \%$ & $18 \%$ & $7 \%$ & $14 \%$ & $7 \%$ \\
1974 Closeness & 10 & 27 & 18 & 16 & 10 & 15 & 4 \\
1981 ID & 13 & 21 & 15 & 12 & 13 & 14 & 12 \\
1981 Closeness & 8 & 25 & 15 & 14 & 9 & 22 & 7 \\
\hline
\end{tabular}

in time. The product moment correlation $(r)$ between the two was 0.85 in 1974 and 0.88 in 1981 - strong evidence for their overlap. Other approaches also show the overlap. For example, if leaners are included in the partisan groupings, very few instances of inconsistent classifications emerge; thus, in 1974 , only $2.7 \%$ of the respondents were Republicans on one scale and Democrats on the other, or vice versa, while in 1981 , the figure was $2.3 \%$.

The two scales are also comparable in their stability over time. Asher (1974) found a 0.83 product moment correlation for the ID measure in the 1956-1960 NES panel; Jennings and Markus (1984) report a coefficient of 0.78 for a 1965-1973 panel of parents, a 0.83 correlation for these parents between 1973-1982, and a 0.77 correlation over the entire seventeen-year period. In the present panel, the product moment stability coefficient of the ID measure is 0.72 . The closeness measure is almost as stable, at 0.71. (See also Converse and Markus, 1979, p. 38; Markus, 1982, p. 549.)

Another measure of stability is the percentage of respondents who possess the same party preference at the two points in time. Summary measures of those in the panel with stable preferences (including leaners) the percentage Democratic, no preference, or Republican at both points in time, regardless of intensity-are given in Table 4.

Similarity in the intergenerational transfer of partisanship provides additional evidence of the overlap between the two scales. Party identification has traditionally been one of the most faithfully transmitted of all political attitudes (Jennings and Niemi, 1974, 1981). The 1974 study contained interviews with 245 pairs of parents and their offspring, of whom 226 gave valid answers for both of the partisanship questions. ${ }^{7}$ The pair correlations $(r)$ for the two measures were quite similar: 0.48 for the closeness measure and 0.54 for ID. Considering that the closeness version

TABLE 4. Preference Percentages at Both Points in Time

\begin{tabular}{llllll}
\hline & & & & \multicolumn{1}{c}{ Total } & \\
& Democrats & No Pref. & Republicans & Stable & Unstable \\
\cline { 2 - 6 } ID & $41.9 \%$ & $6.8 \%$ & $26.4 \%$ & $75.1 \%$ & $24.9 \%$ \\
Closeness & 44.4 & 5.2 & 25.9 & 75.5 & 24.5 \\
\hline
\end{tabular}


relies on spontaneous party declaration and that the young have had little direct experience with the parties, the similarity in transmission rates is all the more impressive. The correlation between the two measures was 0.89 for parents and 0.84 for children.

A traditional strength of the standard measure is its ability to "predict" the vote, though exceptions are not uncommon (see below). Panel data on both measures permit the comparison of their predictive ability. Indeed, the six-year lag between reported party preference in 1974 and presidential vote in 1980 constitutes a stern test of the strength of subjective party attachment measures. The two scales are remarkably similar in their results: The following are the panel percentages of each category from the first wave that reported in the second wave that they voted for the Republican candidate in 1980:

$\begin{array}{llllllll} & 1 & 2 & 3 & 4 & 5 & 6 & 7 \\ \text { ID } & 23 \% & 46 \% & 58 \% & 73 \% & 87 \% & 92 \% & 97 \% \\ \text { Closeness } & 22 & 45 & 53 & 75 & 89 & 94 & 100\end{array}$

Overall, then, the two scales are equivalent in many aspects of the assessment of the direction and the intensity of partisanship.

\section{THE QUESTION OF INDEPENDENCE}

If the measures behave similarly despite their different origins, why should a new approach be preferred over a tried-and-true friend? What are the advantages of the alternative measure? One is that the closeness measure deals better with several problems arising from the ID treatment of independence.

The closeness measure links most respondents with a political party. If it does so improperly - if it classifies people as partisan who in fact are notthe measure would be flawed. There is no evidence that this is the case. Party closeness provides empirical results quite similar to ID. The alternative measure holds up well under close scrutiny. In particular, it eliminates some problems arising from the treatment of independents in the ID scale. The cross-tabulations of the closeness and ID scales for 1974 and for 1981 suggest the origins of some of these problems with independents (see Table 5).

Independent leaners are found in all categories of intensity in the closeness scale, and are slightly more likely to be found in the "fairly close" category than in the "not very close" category, the one that corresponds to the leaners in the ID scale..$^{8}$ Respondents may value independence highly, yet not find it difficult to choose a party they are close to-and often quite 
TABLE 5. Closeness and ID Scales, 1974 and 1981 (in \% of Total Cross Sections, Age $\geq 18$ )

\begin{tabular}{lccccccccc}
\hline & \multicolumn{10}{c}{1974} \\
ID & VCD & FCD & NCD & NPr & NCR & FCR & VCR & $\%$ & $N=$ \\
\hline SD & $8.0 \%$ & 7.3 & 1.0 & .1 & 0. & .3 & .1 & 16.7 & 260 \\
WD & 1.3 & 11.2 & 8.9 & .9 & .3 & .5 & .1 & 23.2 & 362 \\
ID & .8 & 6.8 & 5.1 & 1.2 & .3 & .1 & 0. & 14.3 & 223 \\
IND & .1 & 1.3 & 2.4 & 12.2 & .9 & .6 & .1 & 17.6 & 274 \\
IR & 0. & .1 & .4 & 1.2 & 2.3 & 3.0 & .1 & 7.1 & 111 \\
WR & 0. & .2 & .4 & .6 & 5.5 & 6.9 & .7 & 14.3 & 223 \\
SR & 0. & 0. & 0. & 0. & .2 & 3.5 & 3.1 & 6.7 & 105 \\
Total & 10.3 & 27.0 & 18.2 & 16.0 & 9.5 & 14.9 & 4.1 & $100 \%$ & \\
$N=$ & 160 & 420 & 284 & 250 & 148 & 232 & 64 & & 1558 \\
& & & & & & & & & \\
& & & & 1981 & & & & & \\
SD & 5.9 & 6.3 & 1.0 & .2 & 0. & 0. & 0. & 13.4 & 144 \\
WD & 1.1 & 11.2 & 7.2 & .9 & .1 & .5 & 0. & 20.9 & 225 \\
ID & .4 & 7.2 & 5.5 & 1.4 & .3 & .3 & 0. & 15.0 & 161 \\
IND & .2 & .6 & .8 & 8.8 & .8 & .1 & 0. & 11.3 & 121 \\
IR & 0. & .1 & .6 & 1.7 & 3.3 & 7.1 & .6 & 13.2 & 142 \\
WR & .3 & .1 & .1 & .6 & 3.9 & 8.2 & .7 & 13.9 & 149 \\
SR & 0. & 0. & .1 & .2 & .4 & 6.3 & 5.3 & 12.3 & 132 \\
Total & 7.8 & 25.4 & 15.3 & 13.7 & 8.8 & 22.4 & 6.6 & $100 \%$ & \\
$N=$ & 84 & 273 & 164 & 147 & 94 & 241 & 71 & & 1074 \\
\hline
\end{tabular}

$\mathrm{VC}=$ very close $\mathrm{FC}=$ fairly close $\mathrm{NC}=$ not close; $\mathrm{S}=$ strong; $\mathrm{W}=$ weak; $\mathrm{I}=$ independent.

close to-when asked! This ambiguity helps explain the frequently observed irregularities on the part of independent leaners. The standard ID measure allocates them to a less intense state of party attachment than they actually claim when queried in a different fashion.

Comparison of the closeness and ID measures can thus help resolve some puzzles about the workings of the standard measure. In particular, comparison can also provide insights on several speculations about the nature of independence in American electoral behavior and party politics and the presumed contrasts between the American setting and those of Western Europe.

One insight concerns the distinction between independents, including leaners, and no preference respondents. Coding procedures used in the 1981 American study permit a distinction between the two categories. ${ }^{9}$ The partisan division on the closeness scale of independents and no-preference respondents from the ID scale in 1981 is given in Table 6. Not surprisingly, the no-preference respondents are highly clustered toward the center of the closeness scale. 
TABLE 6. Partisan Division on the Closeness Scale of Independents and No Preference Respondents from the ID Scale in 1981

\begin{tabular}{ccccccccc}
\hline & $\begin{array}{l}\text { Very } \\
\text { Close } \\
\text { Dem. }\end{array}$ & $\begin{array}{c}\text { Fairly } \\
\text { Close } \\
\text { Dem. }\end{array}$ & $\begin{array}{c}\text { Not } \\
\text { Close } \\
\text { Dem. }\end{array}$ & $\begin{array}{c}\text { No } \\
\text { Choice }\end{array}$ & $\begin{array}{c}\text { Not } \\
\text { Close } \\
\text { Rep. }\end{array}$ & $\begin{array}{c}\text { Fairly } \\
\text { Close } \\
\text { Rep. }\end{array}$ & $\begin{array}{c}\text { Very } \\
\text { Close } \\
\text { Rep. }\end{array}$ & $N$ \\
\cline { 2 - 9 } $\begin{array}{c}\text { Independents } \\
\text { (including }\end{array}$ & & & & & & & & \\
$\begin{array}{c}\text { leaners) } \\
\text { No preference }\end{array}$ & $1 \%$ & $22 \%$ & $19 \%$ & $23 \%$ & $11 \%$ & $22 \%$ & $1 \%$ & $(328)$ \\
\hline
\end{tabular}

The same is not so with respect to the independents. Some $77 \%$ of the respondents who claim independence rather than no preference or a party in the ID question in fact choose a party in the closeness version. They are more likely to choose the fairly close than the not-close categories. The label of independent may be attractive, but respondents do not volunteer it unless it is specifically presented as an alternative. And they do not volunteer it even after independent has been mentioned in the interview schedule as an alternative equal to Republican or Democrat. Almost half of these independents are in the two most partisan categories in the closeness version, while the constraints of coding limit them to the category of leaner, at best, in the ID version.

The above properties of independence in the ID scale are closely related to questions concerning intransitivities raised in connection with that measure. These intransitivities refer to nonmonotonic patterns in which many respondents who score high on partisanship according to the ID measure exhibit behaviors and attitudes that seem to reflect weaker partisanship than those who score lower. Using pooled data from the 1952-1972 NES surveys, Petrocik (1974, p. 32) found several intransitivities in political involvement between leaners and weak identifiers, but no intransitivities in partisan-related behavior: Leaners were "less likely to vote a straight ballot and less likely to feel strongly about one party over the other than are identifiers; but they are higher than weak identifiers on all other measures of political involvement." During the time periods covered by the present study, even the strictly partisan variables exhibit some intransitivities in the ID but not in the closeness measures.

Valentine and van Wingen (1980) found similar patterns of intransitivities. They noted that on measures relating strictly to partisanship, such as the attitudes of Democrats toward Democrats and Republicans toward Republicans, independent leaners are always less supportive of their party than are weak partisans. They also showed, however, that leaners were higher than weak partisans on general types of political predispositions such 
as political efficacy, interest in politics, and attempts to influence the vote of others, just as Petrocik had reported.

The ID scale exhibits some intransitivities in voting behavior. The Republican percentage of the two-party vote for president in 1972 (for the 1974 cross section) and in 1980 (for the 1981 cross section) for each category on the two scales is given in Table $7 .{ }^{10}$ An intransitivity appears in the first-wave results for ID: A higher percentage of weak than leaning Democrats reported voting for Nixon in 1972. The closeness scale, by contrast, shows no intransitivities. Moreover, it "spreads" the voters across a wider range of variation than does the standard measure. ${ }^{11}$

The Republican and Democratic party thermometers exhibit patterns similar to voting: There are no intransitivities in the party thermometer scores on the closeness scales, whereas the ID measure shows that weak Democrats felt more warmly than leaning Democrats toward the Republican party in both years and weak Republicans showed greater affection than leaning Republicans for Democrats in 1981. Thus, on these variables, our ID scales exhibit the predicted intransitivities; the closeness scales show far fewer. ${ }^{12}$ Petrocik attributed these intransitivities, in part, to the higher educational levels of independents, which is quite compatible with the results found by Valentine and van Wingen as well as our own. This explanation undoubtedly accounts for some intransitivities, such as efficacy. But another source is certainly the inclusion of partisanship and independence in the same scale; the party closeness measure exhibits far fewer intransitivities on the dimensions examined.

\section{A MEASURE OF "SUPPORT"}

A short detour will consider the treatment of independence in another recent approach to the measurement of party preference. The 1980 NES developed a "support scale" as a new measure of partisanship that promised to resolve some of the nagging problems concerning the dimensionality of the ID measure. Individuals in the present study cannot be located on the

TABLE 7. Republican Percentage of the Two-Party Vote for President in 1972 and in 1980 for Each Category on the Two Scales

\begin{tabular}{llllllll}
\hline & 1 & 2 & 3 & 4 & 5 & 6 & 7 \\
\cline { 2 - 7 } 1972 ID & $26 \%$ & $55 \%$ & $49 \%$ & $76 \%$ & $92 \%$ & $98 \%$ & $99 \%$ \\
1972 Closeness & 19 & 47 & 59 & 77 & 96 & 96 & 100 \\
1980 ID & 13 & 35 & 47 & 81 & 92 & 95 & 98 \\
1980 Closeness & 8 & 33 & 42 & 78 & 91 & 98 & 98 \\
\hline
\end{tabular}


support measure, as it was not included in the questionnaire; but it is possible to profit from a comparison of the marginals.

The battery introduced in the 1980 NES study asked, "In you own mind, do you think of yourself as a supporter of one of the political parties, or not? (If yes, which political party do you support?" Almost $60 \%$ of the 1980 sample responded no, and they were asked, "Do you ever think of yourself as closer to one of the major political parties, or not? (If yes, Here is a scale from 1 to 7 where 1 means feeling very close to the Republican party and 7 means feeling very close to the Democratic party. Where would you place yourself on this scale?"13 The marginal frequencies are as follows: ${ }^{1+}$

$\begin{array}{ccccc}\begin{array}{c}\text { Democratic } \\ \text { supporter }\end{array} & \begin{array}{c}\text { Closer to } \\ \text { Democratic } \\ \text { party }\end{array} & \begin{array}{c}\text { Not closer } \\ \text { to a party }\end{array} & \begin{array}{c}\text { Closer to } \\ \text { Republican } \\ \text { party }\end{array} & \begin{array}{c}\text { Republican } \\ \text { supporter }\end{array} \\ 23.9 \% & 16.0 \% & 33.3 \% & 10.1 \% & 16.7 \%\end{array}$

The most serious consequence of this hybrid measure of party support and closeness is that one-third of the sample ends up without any partisan assignment at all. This is double the percentage of pure independents in the ID scale from the $1980 \mathrm{NES}$ and more than double the percentage in the no-preference categories in the 1974 and 1981 closeness scales. Unless those without a partisan preference turn out to be devoid of any feeling of closeness to either party - which cannot be true given their willingness to make a choice on the traditional ID measure in the same interview schedule-the support question understates the level of partisanship. It may be desirable to screen out respondents without true opinions; but it is also possible that asking first about being a party supporter and then providing a midpoint on a seven-point scale makes it too easy for respondents to remain neutral.

The support measure avoids the problem of independents but creates new ones by discouraging professions of partisan direction. On the other hand, the ID cues of Democrat, Republican, or independent confuse two dimensions. The closeness measure possesses advantages in dealing with both problems.

The previous discussion has underlined a central tenet of survey research: Question wording makes a difference. This is a special concem in cross-national work. A review of problems of comparability in cross-national research is not necessary here. Nevertheless, a few comments will illustrate some dimensions of the problem as they affect the two measures of partisanship. 


\section{A CROSS-NATIONAL COMPARISON}

The differing results of the three measures already discussed underline the importance of question wording. ${ }^{15}$ Yet comparisons between the United States and other countries often ignore differences in how partisanship is gauged. Independence is a serious problem. Cross-national comparisons show that, when the party closeness measure is used, respondents in the United States are no less likely than those of its peer democracies to choose a party rather than independence. Cross-national results with the party closeness scale suggest that national levels of identification with parties are very much a function of the length of experience with democratic elections, as Converse (1969) argued. In the political action surveys of 1974-75, the six countries that used the closeness measure exhibited the following percentages expressing a partisan preference: ${ }^{16}$

$\begin{array}{cccccc}\text { Netherlands } & \text { U.S. } & \text { Finland } & \text { Britain } & \text { Italy } & \text { Switzerland } \\ 83 \% & 82 \% & 82 \% & 81 \% & 73 \% & 59 \%\end{array}$

The high absolute levels and the similarity among the four countries that have a long, largely unbroken history of free elections with universal suffrage are remarkable. By the same token, the lower percentages in Italy and Switzerland are also explicable in terms of each country's political history. ${ }^{17}$

The introduction of independence into cross-national comparisons gives rise to complications. Only in the United States is the phenomenon widespread. ${ }^{18}$ Europeans, Canadians, and others drift into and out of partisanship and no preference; they do not claim to be independents. But then neither do Americans when they are not explicitly offered that choice! This is not to argue that independence is not widespread in the United States, or that it should not be taken into account in comparing Americans with citizens of other countries. Rather, it is a separate dimension that merits separate investigation. Cross-national analyses that rely on ID measures in the United States and closeness measures in other countries cannot deal properly with questions concerning independence and nonpartisanship. Independence is an American phenomenon. It is undoubtedly real, encouraged by registration requirements, and decades if not generations of public discussion. We do not argue that it is purely an artifact of measurement. On the other hand, when Americans are asked the same questions about partisanship that are asked of citizens of most other countries, as in the closeness question, their responses are remarkably similar to those of other countries.

We really don't know much about independence in other countries. 
Judging from the electoral laws and public debate outside the United States, there are few reasons for expecting the phenomenon to be widespread - at least in its American form. It seems tied closely with the ID question for eliciting partisanship. No assumptions about independence should be made when other measures such as the party closeness measure are employed. Cross-national speculation should take into account the results of alternative wording in evaluating partisanship in the United States.

\section{CONCLUSIONS}

Party closeness is similar to ID in many ways. It shares the high reliability of ID, meaning that it is one of the most reliable scales in survey research dealing with political behavior. It divides respondents into categories in roughly the same manner as ID. In its relationship with many other variables it seems to behave quite similarly to ID. By most behavioral criteria the two scales are quite parallel.

The ID measure is one of the treasures of American electoral research. Why then employ the closeness measure instead of the long-used traditional scale? The closeness measure resolves some important irregularities accompanying the ID measure. It taps a single dimension of partisanship and thus eliminates most of the problems associated with independence, which our analyses suggest is a separate dimension. The closeness measure is especially suitable for cross-national comparisons, an advantage that perhaps carries greater weight with comparativists than with Americanists.

The ID measure is unsuitable for use in countries with more than two parties, which means it is unsuitable everywhere except the United States. It is also unsuitable where independence is not a part of the political vocabulary, which likewise means everywhere except the United States. In trying to understand partisanship in its rich diversity, researchers can take comfort in the finding that ID and closeness can, for most purposes, despite the differences in the resulting partisan profiles, be substituted for one another as long as the problem of independence is not at issue.

The closeness scale should be used as an alternative or supplement to ID in some American work. This would ensure that the results reported here are not idiosyncratic to this particular set of studies. It would also facilitate the development of comparability in cross-national electoral studies.

Acknouledgements. Analysis for this article was supported by NSF Grant SES 8420408 to the first-named author. An earlier version was presented at the 1987 Convention of the Mid-West Political Science Association, Chicago, IL, April 9-11, 1987. 


\section{NOTES}

1. For example, Warren Miller employed the closeness measure in Swedish and Dutch, Philip Converse and Roy Pierce in French, and Samuel H. Barnes in Italian surveys in the 1960s. See Miller and Stouthard (1975), Barnes (1977), and Converse and Pierce (1986). The results of the first wave of the eight-nation surveys are reported in Barnes, Kaase, et al. (1979), for the United States, Britain, the Netherlands, Germany, and Austria.

2. Unless clearly noted, all data presented in the present analysis come from these two cross sections (1974 and 1981) and the accompanying panel. The 1974 data are available from the Zentralarchiv (ZA) and the ICPSR (study number 7777 ). The 1981 cross section and panel data are being prepared for release by the $\mathrm{ZA}$ and will be available from the $\mathrm{ZA}$ and the ICPSR.

Both cross sections include respondents age 16 and above. The cross section N's for the United States are 1,719 in 1974 and 1,156 in 1981. The panel $\mathrm{N}$ is 933. Unless stated otherwise, in all of the analyses that follow, 16- and 17-year-olds have been eliminated from the cross sections in order to render the results comparable to NES data. Hence the reduced N's are 1,651 for 1974 and 1,122 for 1981 .

3. German and Austrian versions differ from the measure discussed here for reasons extraneous to the present discussion.

4. Experimentation with placement and inclusion and exclusion of the two questions in different versions of the interview schedule would, of course, be the ideal solution to the types of problems being addressed here. The present design does not meet the criteria of a true experimental design. Yet it is clear that the ability of the closeness question to elicit partisanship is not due to "training" effects in the questionnaire, as the ID version was preceded by several very "political" questions, including the good and bad points of the parties and the meaning of left and right in politics; the closeness question, on the other hand, follows a series of demographic questions-a format unlikely to have the same training effect. Placement effects seem to be minimal.

5. This is not possible in multiparty systems or even in those such as Britain and Germany where the existence of minor parties complicates what is often viewed, incorrectly, as two-party electoral situations.

6. The large percentage of Republican respondents in 1981 in both scales reflects the closeness of the interviewing to the Reagan landslide. Other surveys during this period detected the same surge.

7. When the parent of a child 16-20 fell into the cross-sectional sample, the child was also interviewed, while a parent of each sample respondent 16-20 was likewise interviewed. See Jennings, Allerbeck, and Rosenmayr, 1979.

8. Experimental research suggests several measurement effects that could play a role here (Schuman and Presser, 1981, pp. 54, 177). One is the tendency of respondents to choose moderate response eategories when they are tired. Another is the preference of respondents for the middle category when confronted by three choices (very close, fairly close, and not very close) rather than by strong or not very strong - the alternatives presented by the ID version. Both may have had an impact on the responses.

9. For a full discussion of this issue see Miller and Wattenberg (1983) and Craig (1985). These coding distinctions are available only in the original American data set; they were not included in the three-nation set of common-core questions that are available for distribution through the Zentralarchiv and the Interuniversity Consortium for Political and Social Research.

10. Respondents who were too young to vote in 1972 and 1980 are excluded from the analyses.

11. The closeness measure does not appear to be simply a surrogate for the vote, given the time 
lag between reported vote and declaration of party attachment-the 1974 interviews followed the 1972 election by at least twenty months, while the 1981 lag was at least eight months - though it is possible that closeness is more responsive to short-term forces than is ID.

12. For example, both the strong identifiers and leaners are higher in political interest than weak identifiers in the ID scale, but not in the closeness version. On efficacy, the ID scale shows leaners higher in both years; the closeness version shows weak identifiers higher than leaners. But in both versions, the lowest efficacy scores belong to strong Democrats and the highest to strong Republicans. Differences in education obviously enter here. Results for the ID scale on attempts to influence the vote of others parallel those of Valentine and van Wingen for Democrats in 1974 and for Republicans in 1981; the closeness scale shows no intransitivities on this variable.

13. In the 1982 version the follow-up question simply asked, "Do you ever think of yourself as closer to one of the two major parties, or not? (If yes, Which party do you feel closer to?"

14. These figures are from Weisberg (1983, p. 365); sce also Weisberg (1980) and Dennis (1982). Respondents were also asked, "Do you ever think of yourself as a political independent, or not?" With the responses to this question, respondents can be placed in a ten-category classification according to their response to this question combined with the above five categories (Weisberg, 1983, p. 365). However, this measure and the separate treatment of independence made possible by the new measures are not the concern of the present article. The data are available from the 1980 NES: ICPSR 7,763 .

15. For an example of differences of a similar magnitude in results obtained in Germany due to question wording, see Kaase, 1976.

16. These figures are from the Political Action Cookbook (1979).

17. Swiss women received the vote at the national level only three years before the survey was taken. Italy, of course, suffered twenty years of dictatorship.

18. A review of the literature revealed only one example of the use of the American ID version, including independent as an altemative, in non-American field work. Butler and Stokes (1969) report that a Gallup Poll in Angust 1966 asked "Conservative, Labor, Liberal, or independent," with only $3 \%$ choosing the latter category.

\section{REFERENCES}

Asher, Herbert. (1974). Some consequences of measurement error in survey data. American Journal of Political Science 18: 469-485.

Barnes, Samuel H. (1977). Representation in Italy. Chicago: University of Chicago Press.

Barnes, Samuel H., Max Kaase, et al. (1979). Political Action. Beverly Hills: Sage.

Bastedo, Ralph W., and Milton Lodge. (1980). The meaning of party labels. Political Behatior 2: 287-308.

Budge, Ian, Ivor Crewe, and Dennis Farlie, eds. (1976). Party Identification and Beyond. London: John Wiley.

Butler, David, and Donald Stokes. (1969). Political Change in Britain. New York: St. Martin's Press.

Camplell, James E. (1984). The intervals of party identification: Rescaling the partisan categories. Paper prepared for the 1984 Annual Convention of the APSA, Washington, D.C. 
Converse, Philip. (1969). Of time and partisan stability. Comparative Political Studies 2: $139-171$.

Converse, Philip, and Gregory Markus. (1979). 'Plus ca change .. .: The new CPS election study panel. American Political Science Review 73: 2-49.

Converse, Philip, and Roy Pierce. (1986). Political Representation in France. Cambridge, MA: Harvard University Press.

Craig, Stephen C. (1985). Partisanship, independence, and no-preference: Another look at the measurement of party identification. American Journal of Political Science 29: 274-291.

Dennis, Jack. (1981a). On being an independent partisan supporter. Paper presented at the 1981 Annual Meeting of the Midwest Political Science Association, Cincinnati, $\mathrm{OH}$.

Dennis, Jack. (1981b). Some properties of partisanship. Paper presented at the 1981 Annual Meeting of the American Political Science Association, New York City.

Dennis, Jack. (1982). New measures of partisanship in models of voting. Paper presented at the 1982 Annual Meeting of the Midwest Political Science Association, Milwaukee, WI.

Howell, Susan E. (1980). The behavioral component of changing partisanship. American Politics Quarterly 8: 279-302.

Jennings, M. Kent, Klaus R. Allerback, and Leopold Rosenmayr. (1979). Generations and families: General orientations. In Samuel H. Barnes, Max Kaase, et al. (eds.), Political Action, pp. 449-486. Beverly Hills: Sage.

Jennings, M. Kent, and Gregory Markus. (1984). Partisan orientations over the long haul: Results from the three-wave political socialization panel study. American Political Science Review 78: 1000-1018.

Jannings, M. Kent, and Richard Niemi. (1974). The Political Character of Adolescents. Princeton: Princeton University Press.

Jennings, M. Kent, and Richard Niemi. (1981). Generations and Politics. Princeton: Princeton University Press.

Kaase, Max. (1976). Party identification and voting behavior in the West-German election of 1969. In Ian Budge, Ivor Crewe, and Dennis Farlie (eds.), Party Identification and Beyond, pp. 91-115. London; Wiley.

Kamieniecki, Sheldon. (1985). Party Identification, Political Behavior, and the American Electorate. Boulder, CO: Greenwood.

Keith, Bruce E., David B. Magleby, Candice J. Nelson, Elizabeth Orr, Mark C. Westlye, and Raymond E. Wolfinger. (1986). Further evidence on the partisan affinities of independent "leaners." British Journal of Political Science 16: 155-184.

Markus, Gregory B. (1982). Political attitudes during an election year; A report on the 1980 NES panel study. American Political Science Review 76: 538-560.

Miller, Arthur H., and Martin P. Wattenberg. (1983). Measuring party identification: Independent or no partisan preference? American Journal of Political Science 27: 106-121.

Miller, Warren E., and Philip C. Stouthard. (1975). Confessional attachment and electoral behavior in the Netherlands. European Journal of Political Research 3: 219-258. 
Norpoth, Helmut, and Jerrold Rusk. (1982). Partisan dealignment in the American electorate: Itemizing the deductions since 1964. American Political Science Review 76: 522-537.

Petrocik, John. (1974). An analysis of intransitivities in the index of party identification. Political Methodology 1: 31-47.

Schuman, Howard, and Stanley Presser. (1981). Questions and Answers in Attitude Surveys. New York: Academic Press.

Shively, W. Phillips. (1980). The nature of party identification: A review of recent developments. In John C. Pierce and John L. Sullivan (eds.), The Electorate Reconsidered, pp. 219-236. Beverly Hills: Sage Publications.

Valentine, David C., and John R. van Wingen. (1980). Partisanship, independence, and the partisan identification question. American Politics Quarterly 8: 165-186.

Weisberg, Herbert F. (1980). A multidimensional conceptualization of party identification. Political Behacior 2: 33-60.

Weisberg, Herbert F. (1983). A new scale of partisanship. Political Behatior 5: 363-376. 